\title{
ARQUITETURA DE FRANQUIAS: UM PARALELO ENTRE A PADRONIZAÇÃO ARQUITETÔNICA E A CONSOLIDAÇÃO DE UMA MARCA
}

\author{
Rayssa Gondim Azevedo ${ }^{1}$ \\ Soraya Mattos Pretti ${ }^{2}$
}

RESUMO: O número de franquias se encontra em ritmo crescente em todo o mundo, fazendo com que as empresas busquem formas para a valorização do seu negócio, e para gerar uma expansão rápida e concreta. Desse modo, o objetivo desse artigo é entender como a arquitetura pode ser usada como ferramenta para a consolidação e sucesso de uma empresa. Para a concepção desse estudo, foi feita uma pesquisa bibliográfica narrativa sobre o mercado das franquias, a psicologia das cores e a psicologia ambiental, além de pesquisas de caso sobre métodos, fluxos e padronizações utilizadas por grandes franquias. O trabalho obteve como resultado estratégias que podem ser utilizadas pelas franquias para proporcionar um maior conforto ao cliente, aliando com o objetivo da marca. Conclui-se que existem diversas estratégias arquitetônicas que podem ser utilizadas para a atração do público e, consequentemente, gerar mais lucro para a empresa.

Palavras-chave: Arquitetura. Franquias. Padronização arquitetônica.

ABSTRACT: The number of franchises is growing all over the world, making companies look for ways to enhance their business, and to generate a rapid and concrete expansion. Thus, the purpose of this article is to understand how architecture can be used as a tool for the consolidation and success of a company. For the conception of this study, a narrative bibliographic research was carried out on the franchise market, color psychology and environmental psychology, as well as case studies on methods, flows and standardizations used by large franchises. The work resulted in strategies that can be used by franchises to provide greater comfort to the customer, allied with the brand's objective. It is concluded that there are several architectural strategies that can be used to attract the public and, consequently, generate more profit for the company.

Keywords: Architecture. Franchises. Architectural standardization.

\footnotetext{
I Graduanda em Arquitetura e Urbanismo pela Faculdade Santo Agostinho; Graduanda em Sistemas de Informação pela Instituto Federal de Ciência e Tecnologia da Bahia.

${ }^{2}$ Graduada em Arquitetura e Urbanismo; Mestre em Engenharia Civil; Graduanda em Medicina pela Universidade Federal da Bahia.
} 


\section{INTRODUÇÃO}

A evolução da globalização e da internacionalização dos mercados é evidente. Nesse sentido, uma economia globalizada direciona para estratégias em busca de uma maior competitividade. Entre elas, se encontra o sistema de Franchising como uma estratégia de expansão e desenvolvimento de negócios nacional e internacionalmente, representando uma parte significativa nesse mercado, visto que é aplicado praticamente em todo o mundo e se encontra em ritmo crescente.

De acordo com Bernard (2008), as franquias se popularizaram a partir dos anos I850, nos Estados Unidos, com a demanda de ex-soldados desempregados buscando seu próprio negócio de forma mais segura e prática e do aumento de sistemas promissores de parcerias.

Desse modo, as franquias se destacam, visto que a rede de empresas busca estratégias de negócios para torná-las competitivas, em um sistema de parceria, união e colaboração entre pessoas independentes a frente de uma mesma marca. Em vista disso, o sistema de franchising evidencia a sua suma importância para o desenvolvimento econômico do país e proporcionar às empresas uma expansão mais rápida, concreta e de menor custo, além de dividir a responsabilidade de alavancar o negócio.

Desse modo, a arquitetura se torna uma ferramenta indispensável para o sucesso de uma marca, visto que a ambientação do espaço também tem influência na relação do cliente com a empresa. Rissatto (2020) afirma que quando se trata de arquitetura de sistema de franchising, uma boa identidade arquitetônica é de extrema importância para o reconhecimento da marca, no mercado, pelo público, e uma expressiva comunicação visual.

Levando em consideração as informações descritas, o presente artigo tem como objetivo analisar como padronização da arquitetura pode contribuir para o sucesso de uma franquia, fazendo uma investigação por meio de pesquisas bibliográficas narrativas e estudos de caso das lojas da Cacau Show, Provanza e Lug's.

A pretensão desse trabalho é analisar a influência da arquitetura no poder de decisão de compra dos clientes, investigando o contexto das franquias, a influência das cores, a psicologia ambiental e as estratégias já utilizadas por empresas de destaque no 
Brasil. Deve-se levar em consideração que é extremamente importante criar espaços funcionais e atrativos para os clientes, para que, desse modo, a identidade visual seja facilmente identificada.

\section{METODOLOGIA}

A presente pesquisa se trata de uma pesquisa aplicada, no que se refere a finalidade ou natureza, visto que os conhecimentos acerca da arquitetura de franquias possuem aplicação prática para o desenvolvimento da marca, utilizando-se de pesquisa bibliográfica e estudo de caso. O método é o hipotético-dedutivo, pois são formuladas hipóteses acerca da forma na qual a padronização arquitetônica pode contribuir para o desenvolvimento de uma franquia.

Esta pesquisa será abordada de forma qualitativa, tendo em vista que as características coletadas acerca das franquias não são quantificações numéricas e, segundo Gerhardt e Silveira (2009, p.32), essa abordagem envolve “(...) compreender, explicar, precisão das relações entre o global e o local em determinado fenômeno; observância das diferenças entre o mundo social e o mundo natural (...)", evidenciando o objetivo da pesquisa de compreender o funcionamento das franquias e a influência da arquitetura.

Quanto aos propósitos, a pesquisa é descritiva-exploratório, visto que envolve levantamento bibliográfico e descreve-se as características nas quais se enquadram as franquias, utilizando técnicas como a observação de projetos de franquias já existentes.

De acordo com Gil (2002, p. 42), a pesquisa se enquadra como descritiva por conta da descrição de características e observação sistemática, objetivados na pesquisa em questão, e "embora definidas como descritivas a partir de seus objetivos, acabam servindo mais para proporcionar uma nova visão do problema, o que as aproxima das pesquisas exploratórias", visto que a pesquisa também busca uma maior familiaridade com o problema, construindo hipóteses e tornando-o mais explícito, tal como pesquisas exploratórias.

Para o delineamento do estudo foi realizada uma pesquisa bibliográfica acerca de: histórico das franquias, a sua contextualização, vantagens, o manual arquitetônico e 
identidade visual, psicologia das cores e psicologia ambiental. Além disso, foram realizados estudos de caso sobre três grandes franquias brasileiras: Cacau Show, Provanza e Lug's.

\section{ARQUITETURA X FRANQUIAS}

\section{I Panorama do Franchising}

O termo "franchising" tem origem na língua inglesa e pode ser traduzido como sistema de franquia. De acordo com a ABF (Associação Brasileira de Franchising), o modelo consiste na licença na qual o franqueador concede ao franqueado o direito de uso da marca, distribuição dos produtos, sistema de operação, incluindo tecnologia de implantação, gestão de negócio e padrões de identidade visual, mediante pagamento do franqueado. Já a palavra "franchising", de acordo com Santos (2017), surgiu do termo "franchise" da língua francesa, na qual "fran" significa concessão de um privilégio ou autorização.

De acordo com Ribeiro et al (20II), no livro Gestão Estratégica do Franchising: Como construir Redes de Franquia de Sucesso, a conceituação de Franchising surgiu nas “cidades francas” da França, na Idade Média, quando a Igreja Católica concedeu licença para que os senhores de terra distribuíssem cartas de franquia para as pessoas em troca de um pagamento, para que pudessem comercializar produtos e serviços.

Alguns pesquisadores apontam a Igreja Católica como os pioneiros do franchising, pois as igrejas são controladas pelo Vaticano e possuem várias unidades espalhadas, sendo os padres os franqueadores, a paróquia como a franquia, a bíblia como o manual, a cruz como o logo e o dízimo como os royalties. (CENTRAL DO FRANQUEADO, 2019).

O primeiro negócio com um sistema de franchising similar ao atual foi em 1731, nos Estados Unidos, quando Benjamin Franklin criou uma parceria com Thomas Whitmarsh na qual exigia que o negócio estivesse sob gerenciamento e direção de ambos durante o acordo. Mais de um século depois, surgiu na Alemanha a cervejaria Spaten-FranziskanerBräu, na qual concedeu o direito de venda dos produtos e uso da marca em troca de pagamento. (CENTRAL DO FRANQUEADO, 2019). 
Entretanto, o sistema franchising na forma empresarial e ampla, como na atualidade, surgiu em meados de 1850 nos Estados Unidos, quando a empresa Singer Sewing Machines Corporation, uma manufatura norte-americana de máquinas de costura, passou a compartilhar os seus métodos de produção e a licença para o uso da marca aos revendedores dos seus produtos, sem ligação com a empresa. (RIBEIRO et al, 20II).

A empresa norte-americana de máquinas de costura licenciou, naquele ano, o que é chamado de know-how na atualidade e o seu pioneirismo no método e patenteação de máquinas de costura e o sucesso no ramo, garantiu que a Singer seja a maior fabricante mundial de máquinas de costura doméstica e i7o anos de história. (RIBEIRO et al, 20II).

Antes dos anos 1900, nos Estados Unidos, surge a primeira franquia de serviços do mundo: a Harper Cabeleireiro, na qual a empreendedora Martha Matilda Harper abriu o seu salão de beleza e, com o sucesso, passou a ensinar seus métodos por meio de um contrato de franchising. (CENTRAL DO FRANQUEADO, 2019). Surgiu também a produtora de automóveis General Motors Corporation na qual iniciou a expansão de pontos de vendas, originando as concessionárias de veículos da atualidade. (RIBEIRO et al, 20II).

Além disso, surgiu o sistema de Franquia de Fabricação através da Coca-Cola, na qual concedeu licenças para que seus produtos fossem produzidos, comercializados e distribuídos, através da contratação de franchising e a exigência de processos rigorosos e utilizações de fórmulas. Essas ações garantiram a expansão dessas empresas, nas quais buscaram controlar a qualidade dos produtos, em diferentes locais, com um investimento menor e um método concretizado no mercado. (RIBEIRO et al, 20II).

A partir de 1900, também nos Estados Unidos, surgiram, dentro do sistema de franchising, mercearias como a Piggly Wiggly, a locadora de veículos, Hertz Rent-a-Car, e a primeira franquia de rede de alimentação de fast-food, a A d W Root Beer (RIBEIRO et al, 20II), além de postos de combustíveis franqueados por distribuidoras de petróleo. (CENTRAL DO FRANQUEADO, 2019).

Após a Segunda Guerra Mundial, nos Estados Unidos, com muitos soldados desempregados e sem experiência, surgiram oportunidades em possuir um negócio próprio, de forma mais segura, através das redes de franquias que surgiam e estavam, cada vez mais, se expandindo. (RIBEIRO et al, 20II). Posteriormente, na década de 1950, surgiram as 
mais famosas redes de franquias no setor de alimentação: Burger King, Kentucky Fried Chicken (KFC), McDonalds e Dunkin' Donuts. (CENTRAL DO FRANQUEADO, 2019).

$\mathrm{Na}$ década de 1960, as franquias passaram a se expandir mundialmente, chegando, inclusive, ao Brasil, com as redes de escolas de idiomas Yázigi e CCAA, em um sistema bem menos estruturado do que posteriormente, baseando-se em transferência de know-how, pelo material didático. (RIBEIRO et al, 20II).

Quando o franchising passou a ser aplicado como estratégia de expansão internacionalmente, na década de 1970 , se tornou mais organizado e abrangente. Nesse período, chegou ao Brasil O Boticário e o McDonald's, atualmente, a primeira e segunda empresa, respectivamente, com maior número de unidades em um ranking nacional, além do surgimento de shoppings, favorecendo a instalação de franquias. (ABF, 202I).

Em 1987, quando o sistema do franchising se fortalecia ainda mais no país, surgiu a Associação Brasileira de Franchising (ABF), para organizar o sistema. Posteriormente, foi regulamentado, através da Lei no 8.955/1994, regendo o contrato de franchising, transmitindo maior segurança para o investimento. Desse modo, o crescimento contínuo do sistema de franchising se intensificou em 2015, por conta da forte internacionalização das franquias brasileiras e do aprimoramento dos processos com a utilização da internet.

\section{3,2 Vantagens do Franchising}

Para Filho et al. (2013, p. 47): "Franchising é um tipo de arranjo comercial em que o franqueador concede a um franqueado uma franquia de seu negócio”. Ou seja, significa conceder acesso algo que antes exclusivo. Tendo isso em vista, Maricato (2006) afirma que esse sistema proporciona benefícios tanto aos franqueadores, quanto aos franqueados.

Nesse sentido, pode-se listar, quanto ao franqueador: a possibilidade de expansão do seu negócio em diferentes localidades, de uma forma mais rápida e com menor investimento (tendo em vista o valor que seria necessário no caso do franqueador abrir todas as sedes em diferentes locais) ocupando espaço no mercado mais rapidamente, fortalecendo a marca e a publicidade, recebe recursos dos sócios (através da taxa de admissão e royalties), além disso, Plá (200I) destaca o reforço, diluindo a responsabilidade 
com relação a impulsionar a marca, visto que são diferentes unidades unidas em uma só marca.

Quanto ao franqueado, pode-se citar: possibilidade de iniciar um negócio com uma marca consolidada no mercado, com credibilidade, tecnologia, metodologia, produtos e marcas testados, além de receber um Manual com todas as instruções para a implantação do negócio, garantindo um melhor planejamento de custo de instalação. Além disso, de acordo com Plá (20oI) pode-se ressaltar a segurança, visto que é menos arriscado do que abrir um negócio próprio, do zero e recebe orientação e assistência na administração do negócio e os benefícios da expansão da rede.

\subsection{Manual de arquitetura e a identidade visual}

Mais que apenas as cores, símbolos ou a fonte do letreiro da fachada, a identidade visual evoca a essência da empresa, seus valores objetivos e personalidade. É a partir dela que as demais decisões serão tomadas. Para uma rede de franquias, este âmbito merece ainda mais atenção já que ao replicar a marca, é necessário que o DNA daquela corporação seja mantido, para que o público consiga reconhecer e identificar de maneira instantânea (RISSATTO, 2020).

Para Caixeiro e Rodrigues (2020) a padronização das franquias é de suma importância, visto que as unidades precisam ter uma comunicação visual clara entre si e com as características da marca. Vale ressaltar que os investidores que buscam franquias nas quais confiem, além da rentabilidade de retorno, esperam credibilidade, fator definido por ser uma marca forte e reconhecida. Além disso, é relevante que as estratégias de branding estejam atrelados ao desenvolvimento do projeto de identidade arquitetônica da franquia.

Para tanto, é necessário que, desde o princípio, o planejamento esteja atrelado a imagem da franquia na qual será distribuído no espaço físico da franquia. Segundo Rissatto (2020), é a padronização da identidade arquitetônica encontrada em todas as unidades das franquias que permitirá que diferentes sedes tenham resultados semelhantes aos das lojas já abertas em outros pontos comerciais. Desse modo, se faz necessário um projeto de arquitetura que siga as orientações especificadas no Manual.

Rissatto (2020) afirma que o manual técnico permite que o franqueador expanda o seu negócio de forma estruturada e planejada para criar uma identidade arquitetônica, de 
acordo com a marca e com o que a empresa quer transmitir ao público. A arquiteta, Rissatto (ANO), ainda pontua:

É essencial pensar na combinação de elementos como materiais, mobiliário, cores, layouts, tipografia que será usada, aplicação do logo, a comunicação visual e outra série de itens. Tudo isso compõe uma excelente ambientação. Além disso, todos esses elementos devidamente em sintonia fazem com que o cliente reconheça facilmente a intenção da marca. (RISSATTO, 2020, p)).

De acordo com Caixeiro e Rodrigues (2020), o layout, as cores, o design e o logotipo devem ser atrelados entre si, fazendo necessário o investimento na identidade visual da marca, para que se torne coesa e sólida. Com esse intuito, a arquitetura utiliza-se de elementos como o design, materiais, tipo de mobiliário, estilo da fachada, disposição dos espaços e ambientação.

\subsection{Psicologia Ambiental}

A Psicologia Ambiental é uma subdivisão da Psicologia, na qual é atrelada a Arquitetura e ao design ergonômico, tal como a Geografia, Ecologia e Recursos Humanos. Embora o tema seja pouco difundido no meio científico, seu estudo contribui para uma melhor compreensão da relação do indivíduo com o ambiente, em uma convivência evolutiva e de qualidade. Se trata do estudo das interrelações entre as pessoas e o espaço físico e social, de modo a "analisar como o indivíduo avalia e percebe o ambiente e, ao mesmo tempo, como ele está sendo influenciado por esse mesmo ambiente" (MOSER, 1998).

Desse modo, enquanto a arquitetura se relaciona com a construção dos ambientes, a psicologia ambiental se relaciona com os fatores psicológicos dentro de um espaço. Em vista disso, quando há uma compreensão da natureza humana, é possível concluir a necessidade de ambientes nos quais possam interagir com privacidade em relação a pessoas próximas ou estudos que aprontam os efeitos positivos de conteúdos neutros e paisagens naturais, contrastando com as paisagens urbanas (PINKER, 2010; JOYE, 2007).

Tendo em vista que o ambiente influencia o comportamento do indivíduo e suas percepções, é necessário que, ao projetar um espaço, seja pensado no bem-estar dos usuários. Desse modo, os componentes no interior de estabelecimentos, como iluminação, 
cores, decoração e música ambiente estão diretamente ligados a tomada de decisões dos clientes, melhorando a satisfação dos consumidores e uma vantagem para a empresa no mercado. (BAKER; GREWAL; PARASURAMAN, 1994).

Dentro do sistema de marketing, Solomon (2011, apud BARBOSA, 2014) afirma que os sentidos (visão, audição, olfato paladar e tato) são elementos importantes para atrair os indivíduos. Desse modo, a visão de Kotler (1973) acerca das lojas é a utilização dos sentidos, descrita em termos sensoriais. Nesse sentido, Kotler (1973) elaborou um modelo para explicar a relação entre a atmosfera da loja e a possibilidade de compra explicar a influência que a atmosfera de loja exerce na probabilidade de compra, verificado na figura I.

Figura I: Relação entre a atmosfera da loja e a possibilidade de compra

(1)

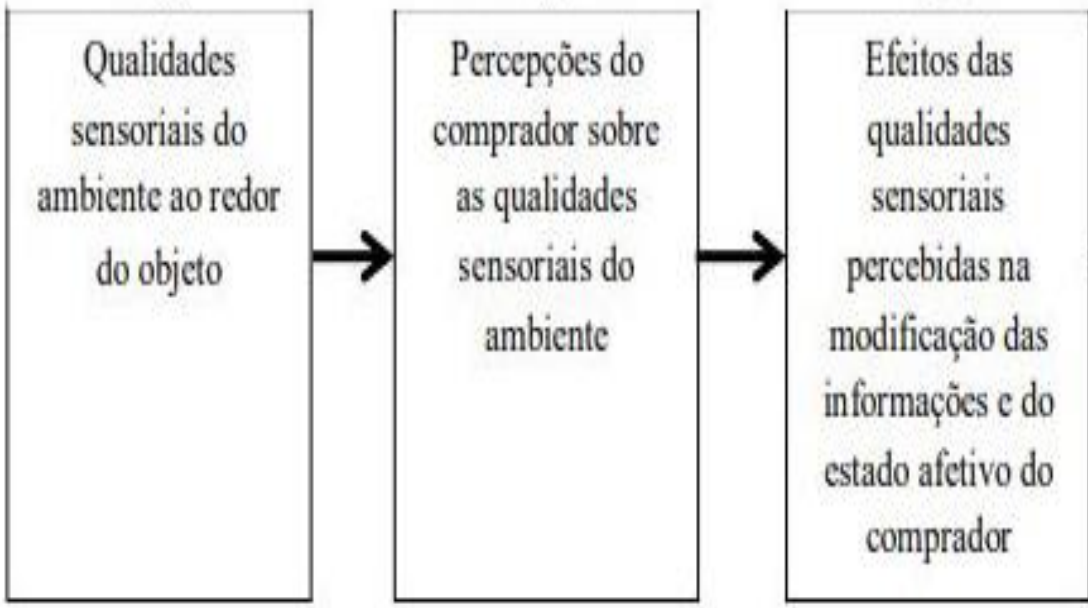

(4)

$\rightarrow \begin{gathered}\text { Impacto da } \\ \text { informaçào e } \\ \text { estado afetivo } \\ \text { modificados na } \\ \text { probabilidade de } \\ \text { compra }\end{gathered}$

Fonte: Barbosa (2014, p.5o)

\subsection{Influência das Cores}

De acordo com Pedrosa (2008), a cor é considerada um efeito sem composição material provocado pela luz sobre os olhos, ou seja, não possuem cor própria. Desse modo, a cor se altera de acordo com a incidência de luz. Farina (1975) aborda a cor como uma realidade sensorial, na qual influencia diretamente as emoções.

Lacy (1996) afirma que a cor influencia diretamente um ambiente e as reações das pessoas dentro dele. Desse modo, é possível afirmar o significativo impacto que as cores 
têm com relação às pessoas, podendo mudar as experiências e a maneira de ver produtos e ambientes. Tendo isso em vista, pode-se comprovar que as cores podem ser um fator de suma importância para o marketing, a experiência dos clientes e para atrai-los.

Em pesquisa da CCICOLOR (2003 apud MORTON, 2019), foi revelado que, dentro de 90 segundos da primeira impressão, o subconsciente de uma pessoa avalia um ambiente ou produto entre 62\% e $90 \%$ apenas por meio das cores. De acordo com a Loyola University (2018 apud MORTON, 2019), a cor é responsável por até 80\% da marca.

Segundo pesquisa da Secretariat of the Seoul International Color Expo (2004 apud MORTON, 2019) no que se relaciona ao marketing e as cores, 92,6\% das pessoas afirmam que o fator visual é o mais importante no mesmo de comprar.

Quando se trata de uma marca, não é aconselhável o uso de cores por moda e, sim, o segmento do negócio, tendo em vista que deve ser chamativo e surtir efeito independente da estação ou tendências anuais. Para isso, segundo Belmudes (202I) é necessário entender os efeitos das cores, pois as cores quentes causam emoções mais expressivas e vivas, enquanto.

De acordo com análise da Towergate Insurance (2017 apud HARKLESS, 2017), existem cores que são utilizadas nos logos e estão ligadas a emoção gerada. Por exemplo, em restaurantes, o verde é associado ao bem-estar e alimentação saudável, o vermelho indica cuidado e vitalidade, estimula o desejo e é associado a movimento, excitação e promoções, enquanto o rosa está associado a produtos doces e meigos, como pode ser verificado na figura 2 abaixo.

Figura 2: Psicologia das cores em restaurantes

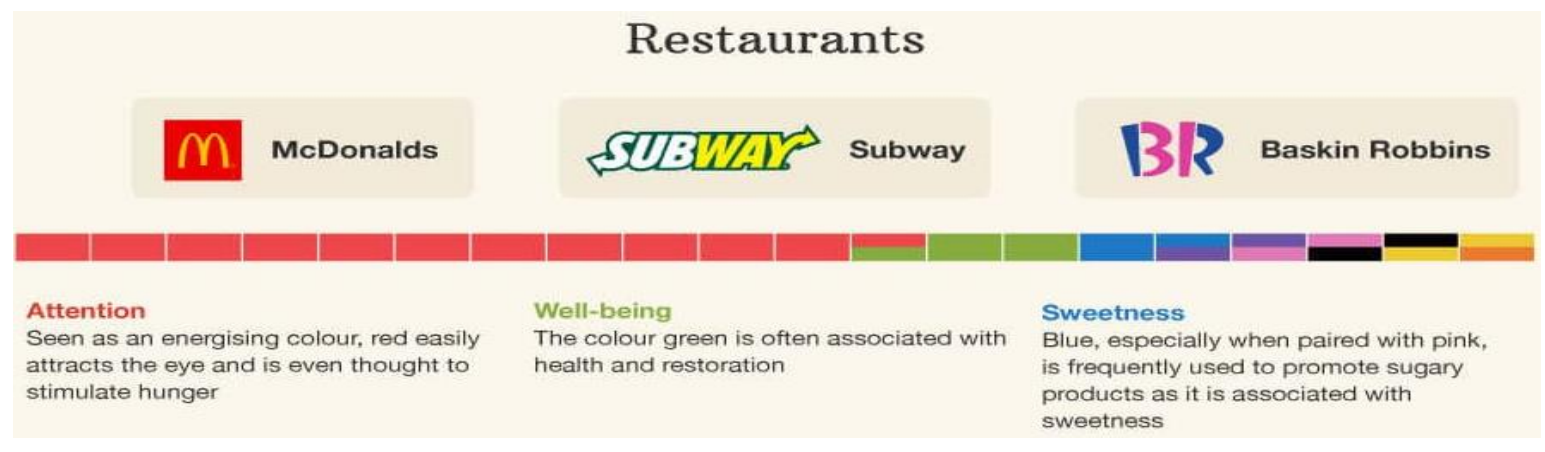

Fonte: Towergate Insurance, 2017. 
Proence, Forastieri, Domingues (2019, p. 94 apud (significa citado por) SANTOS; MARQUES; BARBOSA; CABRAL; LISBOA; SANTOS, 2014) apontam cores e a respectiva associação aos significados no segmento alimentício, "são: o Laranja (não amarelado) que tem poder de instigar o apetite, o rosa é associado a doces, o marrom, remete ao chocolate e o púrpura tem bons resultados quando se trata de vinhos e licores".

\section{ESTUDOS DE CASO 4.I Cacau Show}

A Cacau Show é uma marca de chocolates finos, fundada em 1988, na qual se tornou uma franquia em 2004. Em 2020, a ABF a apontou como a terceira maior franquia no Brasil, por número de unidades, atrás, somente, do O Boticário e do McDonald's, sendo a segunda maior marca de origem brasileira e a maior no segmento alimentício. Além disso, a rede de chocolates finos é considerada a maior do mundo, possuindo mais de 2.500 unidades espalhadas em todo o país.

A marca possui modelos de negócio que variam entre quiosques (premium e express), containers (figura 3) e lojas convencional e smart. É necessária uma área mínima de $8 \mathrm{~m}^{2}+$ área de estoque no primeiro caso, seguido por $30 \mathrm{~m}^{2}$ com $15 \mathrm{~m}^{2}$ de área interna nos containers e $28 \mathrm{~m}^{2}+12 \mathrm{~m}^{2}$ de estoque no caso das lojas.

Figura 3: Modelo de Container da Cacau Show

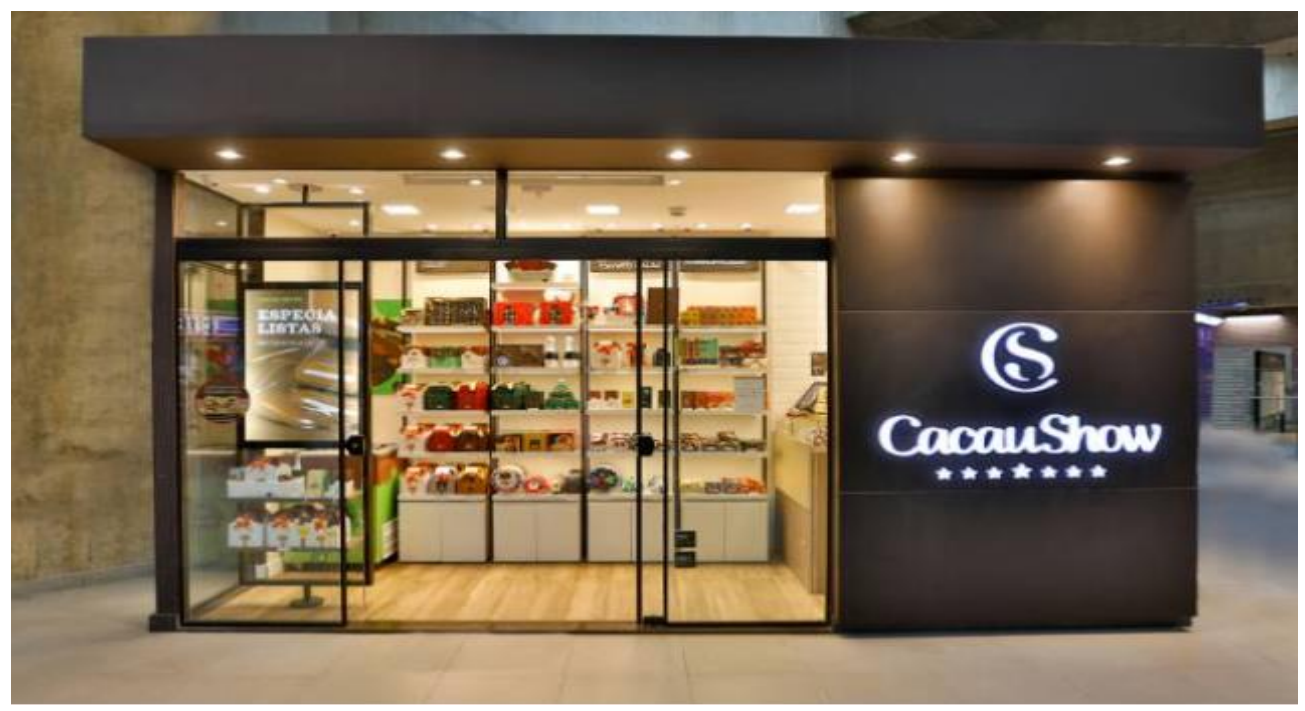

Fonte: Cacau Show, 2020. 
A empresa possui um Visual Merchandising (VM) estudado e estratégico, no qual as técnicas de exposição e a visibilidade dos produtos induzem o cliente à compra. A vitrine e área de vendas, através das cores, organização e exposição dos produtos remetem a marca e criam a identidade.

A madeira e as cores claras são utilizadas com a intenção de promover conforto ao cliente. Além disso, a utilização da cor marrom transmite ao cliente uma sensação de sofisticação e remete diretamente ao cacau e a chocolate, enquanto o verde é associado ao meio ambiente e transmite uma sensação de tranquilidade, conforme como pode ser exposto na figura 4 .

Figura 4: Interior da Cacau Show

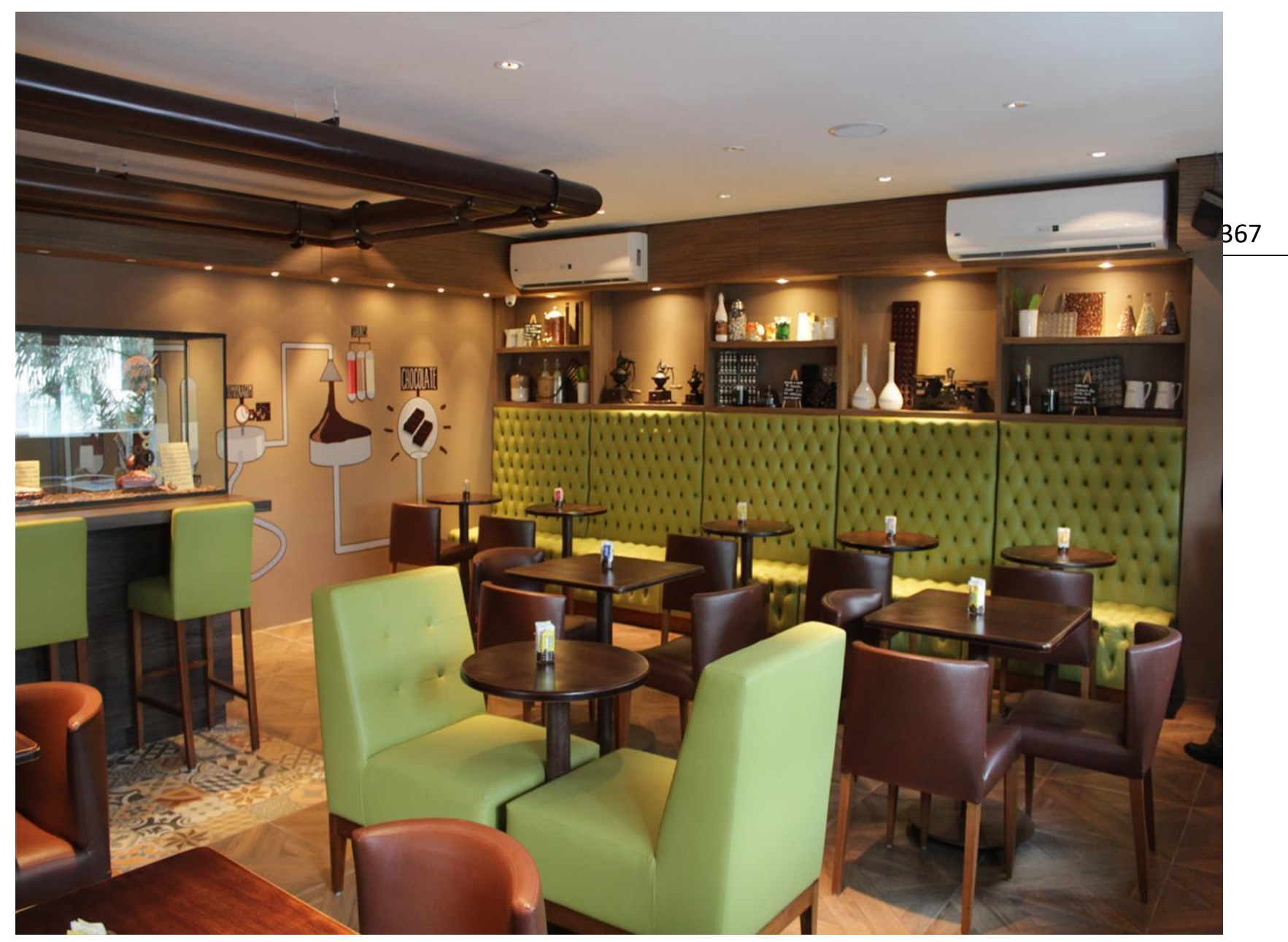

Fonte: Mariana Ulhôa Cintra, 2013. 
Pelo que foi observado, não há uma fachada padrão a ser seguida, embora sempre haja a utilização de vidro, como uma grande vitrine, para que se possa ver a exposição dos produtos mesmo estando do lado de fora, além de ter a logo iluminada, como pode ser verificado nas figuras 5 e 6 .

Figura 5: Fachada da Cacau Show

Figura 6: Fachada da Cacau Show

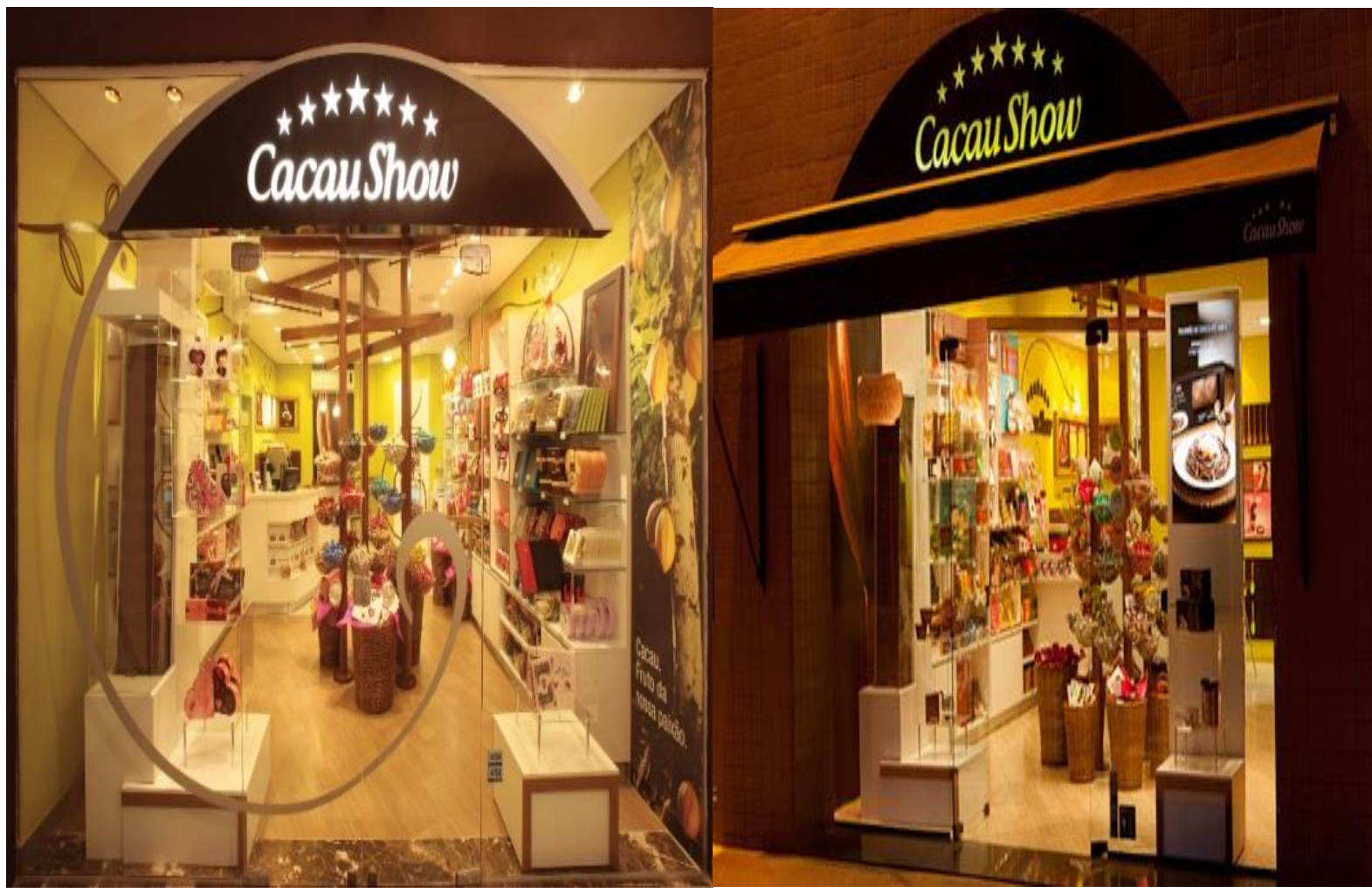

Fonte: Correio dos Municípios, 2021.

Fonte: O São Gonçalo, 2021.

\section{4,2Provanza}

A Provanza é uma indústria de cosméticos e casa de chá surgida em 2004. O setor de franquias conta com mais de 30 lojas em todo o Brasil oferecendo produtos para casa, corpo, cabelo, perfumes, maquiagens e chás gourmets e orgânicos e é inspirado na região francesa de Provença, conhecida pelos floridos campos de lavanda.

A empresa busca, através do projeto, um espaço aconchegante com pontos atrativos e interativos com o usuário, proporcionando ao cliente um sentimento de bem-estar, a fim 
de fazer com que se sinta à vontade em permanecer mais tempo no espaço para conhecer os produtos. As lojas utilizam-se muito da cor roxa, remetendo diretamente aos campos de lavanda, e madeira, fazendo referência a natureza e trazendo a sensação de aconchego.

Embora não tenha uma fachada especifica a ser seguida, a loja inteira é considerada uma vitrine, fator que pode ser observado nas figuras 7 e 8 , através da utilização de paredes de vidro, nas quais possibilitam a visibilidade do interior da loja. Além disso, é utilizada a cor da marca, evidenciando o nome, e os boiseries, remetendo a decoração clássica francesa.

Figura 7: Fachada da loja Provanza

Figura 8: Fachada da loja Provanza

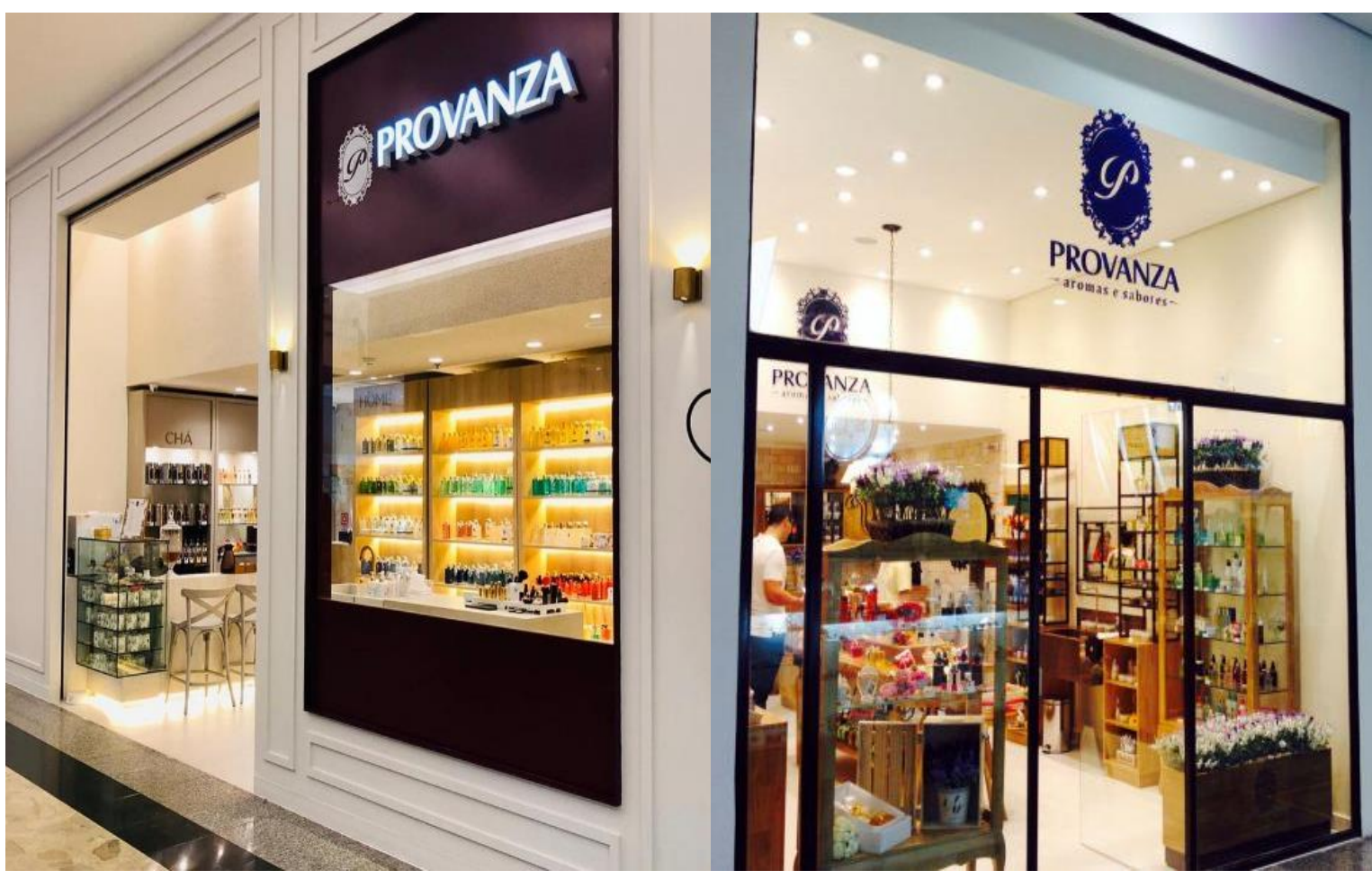

Fonte: Baruck Construtora, 2019.

Fonte: Nathalia Goulart, 2015.

É válido ressaltar que as lojas contam com espaços para lançamentos da marca e o foco em dois diferenciais: a área externa e o espaço de aromaterapia. O espaço de aromaterapia, um local para permanência, conta com um balanço, como pode ser visto na figura 9, para que os visitantes tirem foto para redes sociais e atingindo novos públicos. Além disso, a área externa, com a casa de chás, conta com sofás e poltronas confortáveis, para uma experiência mais agradável, como exposto nas figuras io e II. 

da casa de chás

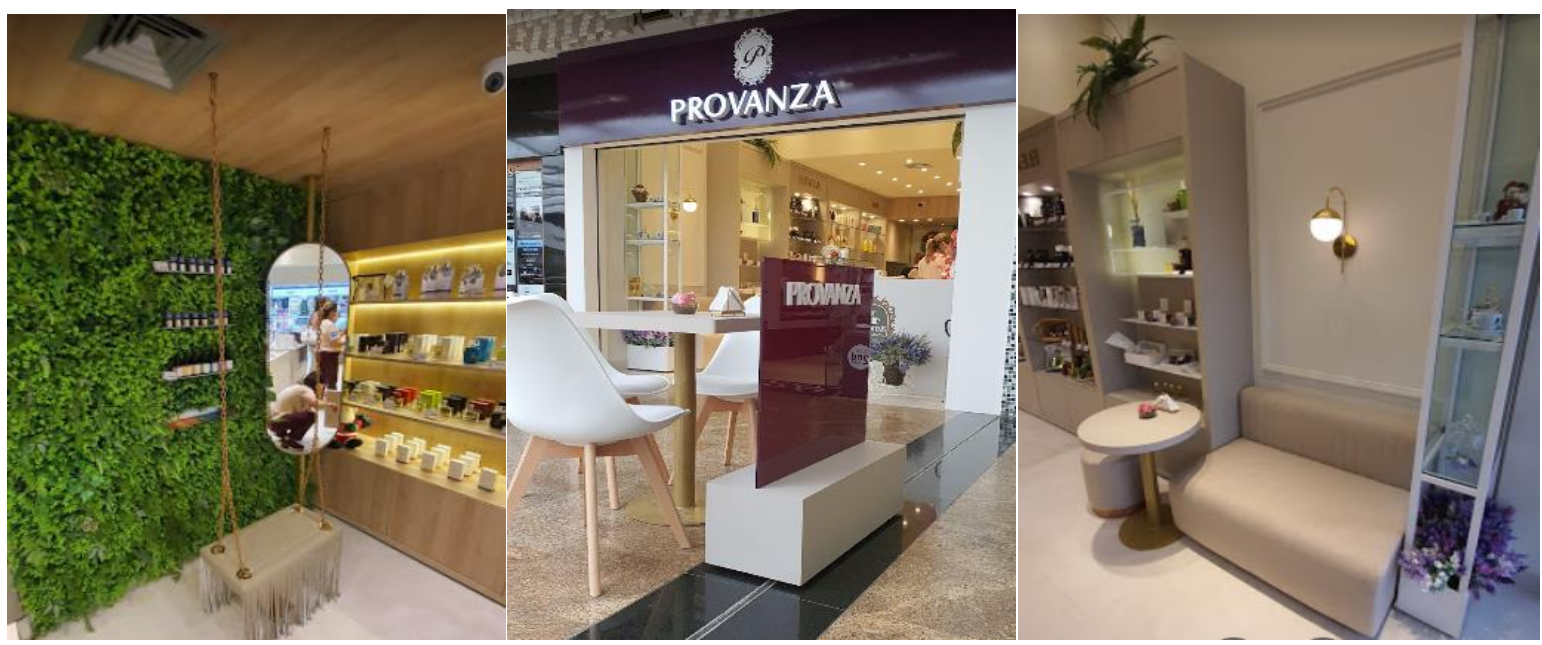

Fonte: Provanza Santos, 2020.

Os vidros das vitrines das lojas devem ser obrigatoriamente laminados ou temperados, incolores, lisos e transparentes e com espessura mínima de io $\mathrm{mm}$. Os letreiros da fachada devem ser luminosos, em letra caixa com acabamento em pintura branco neve com frente em acrílico branco translúcido e a caixa do letreiro deverá ter profundidade de $6 \mathrm{~cm}$. Além disso, é necessário o uso da cor da marca sempre ao fundo da logomarca, podendo ser aplicado em chapa metálica, ACM fosco ou alvenaria, como pode ser verificado na figura 15 .

Figura 12: Fachada da loja Provanza

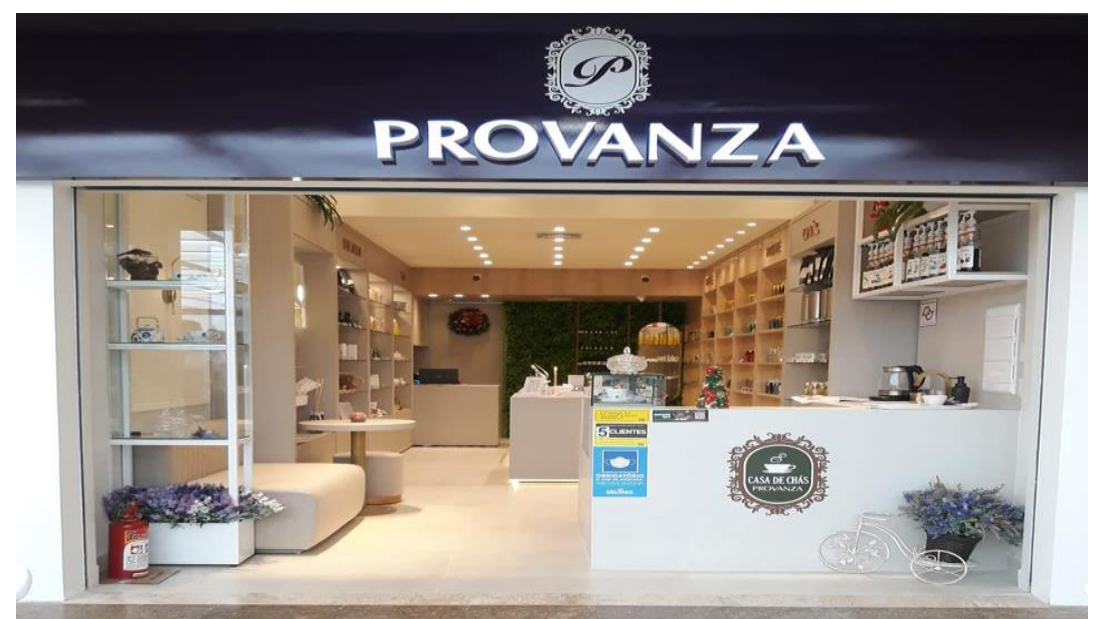

Fonte: Baruck Construtora, 2019. 
Os metais e arandelas são padronizados na cor dourada matte. Os mobiliários e decorações devem permitir livre acesso às caixas de inspeção das instalações elétricas e telefônicas, além dos dispositivos e equipamentos das instalações de exaustão, ventilação, ar-condicionado e de proteção contra incêndio.

\subsection{Lug's}

O Lug's é uma das maiores redes de frango no balde e batata belga do Brasil. Pertencente ao holding de franching, L7 Group, desde 2009, possui mais de i6o unidades, com sedes no Brasil, outros sete países da América do Sul e Portugal.

O manual de implantação da marca conta com uma descrição detalhada dos materiais, cores e medidas que deverão ser utilizados nos pisos, paredes, portas, marcenarias e teto, além da especificação de iluminação, mobiliários e proposta de fachada.

Embora a marca utilize muita madeira, tijolinhos e detalhes e revestimentos na cor preta, com a ideia de trazer conforto aos clientes, através de tons neutros, se trata de uma rede de fast-food, fato que é evidenciado pelo intenso uso das cores amarelo e vermelho, com uma percepção de alegria e urgência, como pode ser verificado na figura i6. Essas cores são utilizadas em fast-foods, com a intenção de promover uma maior rotatividade entre os cliente, consumindo rapidamente e saindo do local.

Figura 13: Fachada da loja Lug's

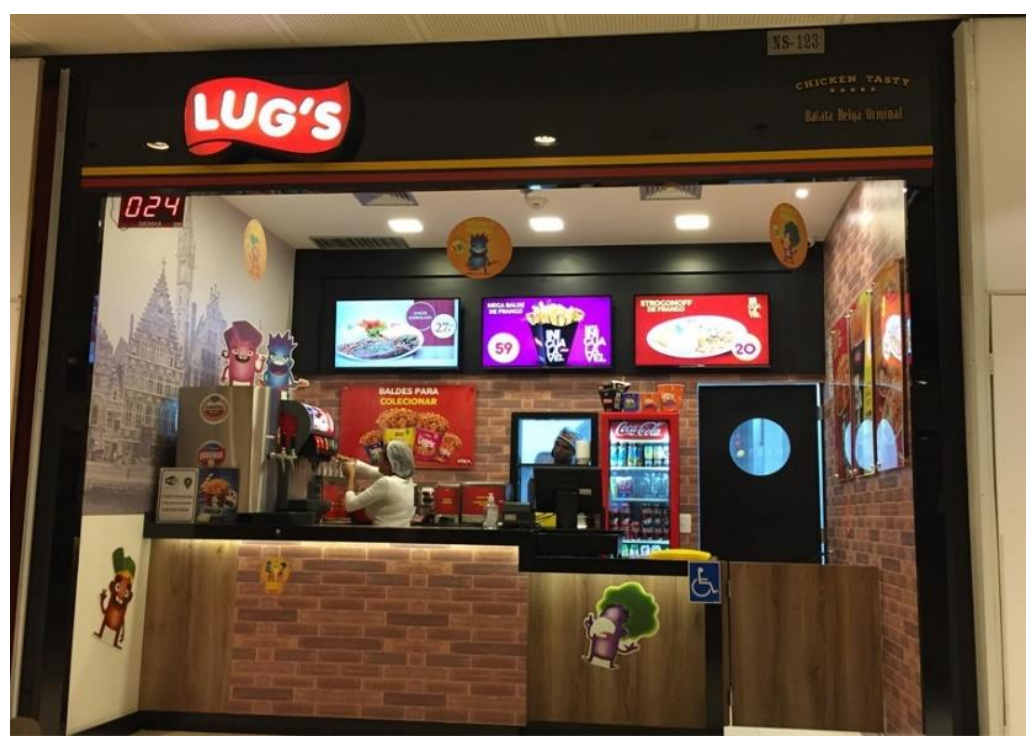

Fonte: Franchsing book, 2020. 


\section{CONSIDERAÇÕES FINAIS}

Diante do exposto, pode-se afirmar que o mercado de franchsing se encontra em ritmo ascendente em todo o mundo, devido, principalmente, ao lucro que esse tipo de negócio pode proporcionar ao franqueado de uma empresa. Nesse sentido, é imprescindível que, ao se criar uma franquia, alguns fatores sejam considerados visando uma consolidação da marca.

Pode-se afirmar, por meio da psicologia ambiental, que o homem é influenciado pelo meio em que está inserido, aumentando ou diminuindo o seu poder de decisão de compras. Nesse sentido, existem algumas estratégias que podem ser utilizadas, visando uma maior atração de clientes ou consumidores dos produtos que estão sendo ofertados pela empresa.

Ademais, existem outros pontos que devem ser levados em consideração como o uso da psicologia das cores, de modo que sejam utilizadas atreladas ao objetivo que o franqueador deseja ofertar com a sua marca, visto que elas podem transmitir sensações e influenciar nas emoções dos consumidores.

Por fim, é válido ressaltar que é imprescindível que a empresa faça a contratação de um profissional especializado para a criação de um manual de padronização arquitetônica, visando a criação de uma identidade visual sólida e coerente para a empresa. Pode-se afirmar, portanto, que a arquitetura é extremamente importante para o mercado de franquias.

\section{REFERÊNCIAS}

6 EXEMPLOS de técnicas de construção sustentável para arquitetura. TotalCAD, 2018. Disponível em: < https://blog.totalcad.com.br/construcao-sustentavel-para-arquitetura>. Acesso em: 26 mai. 2021.

Acreditando na economia: Cacau Show planeja abrir mais 50o lojas em 2021. Correio dos Municípios, 2018. Disponível em: < https://www.correiodosmunicipiosal.com.br/202I/or/cacau-show-planeja-abrir-mais-500-lojas-em-202I/ >. Acesso em: 26 mai. 202I.

A HISTÓRIA do franchising no Brasil e no mundo. Central do Franqueado, 2019. Disponível em: < https://centraldofranqueado.com.br/blog/historia- 
franchising/\#: :text=Especula\% $\mathrm{C}_{3 \%} \mathrm{~A}$ 7\% 3 3\%B5es\%20\%C3\%Ao\%2oparte\%2C\%20a\%2opal avra,regalias\%20em\%2otroca\%2ode\%2oserventia>. Acesso em: I5 mai. 2021.

ALVES, Nadine. 8 opções de materiais sustentáveis para a Arquitetura. Construct, 2017. Disponível em: 〈https://constructapp.io/pt/materiais-sustentaveis-para-arquitetura/〉. Acesso em: 28 mai. 2021.

ASSOCIAÇÃO BRASILEIRA DE FRANCHISING (ABF). Desempenho do Franchising 2020. Disponível em: <https://www.abf.com.br/wpcontent/uploads/202I/03/Desempenho-Franchising-2020-e-50-Maiores-Franquias.pdf>.

Acesso em: 20 mar. 2021.

ASSOCIAÇÃO BRASILEIRA DE FRANCHISING (ABF). Desempenho do Franchising 2019. Disponível em: <https://www.abf.com.br/wpcontent/uploads/2020/03/desempenho-do-franchising-brasileiro-2019.pdf $>$. Acesso em: 22 mar. 2021.

ASSOCIAÇÃO BRASILEIRA DE FRANCHISING (ABF). Estudo ABF das so Maiores Franquias do Brasil 202I reafirma maturidade das redes. Disponível em: 〈https://www.abf.com.br/estudo-abf-das-5o-maiores-franquias-do-brasil〉. Acesso em: 20 mar. 2021.

BAKER, Julie; GREWAL, Dhruv; \& PARASUMARAN Parsu. (1994). The Influence of Store Environment on Quality Inferences and Store Image. J Acad Mark Sci, v.22, n.I, p.328-339, 1994. Disponível em: https://www.researchgate.net/publication/225946714_The_Influence_of_Store_Environme nt_on_Quality_Inferences_and_Store_Image>. Acesso em: 29 mai. 202I.

BARBOSA, Ohana. Estímulos táteis no ambiente de varejo: investigando a experiência de consumo de indivíduos com deficiência visual na perspectiva transformativa do consumidor. Dissertação (Mestrado em Administração) -Universidade Federal do Pernambuco, Recife, 2014. Disponível em: https://repositorio.ufpe.br/bitstream/123456789/12247/r/DISSERTA\%c3\%87\%c3\%83O\%2 oOhana\%2oTrajano\%2oBarbosa.pdf $>$. Acesso em: 27 maI. 202I.

BERNARDES, Marina; CECCONELLO, William; MARTINS, Marcele. PSICOLOGIA AMBEINTAL APLICADA À ARQUITETURA. IN: MOSTRA DE PESQUISA E PÓS-GRADUAÇÃO IMED, 6., 2012, Porto Alegre. Anais eletrônicos... Porto Alegre: CIAPEX, 2012. Disponível em: $\langle$ https://www.imed.edu.br/Uploads/marcelesallesmartins(\%(3\%Arrea3).pdf $>$. Acesso em: 26 mai. 2021.

BRASIL ocupa o $4^{\circ}$ lugar no ranking mundial de construções sustentáveis certificadas pela ferramenta internacional LEED. Green Building Council Brasil, 2018. Disponível em: 
〈https://www.gbcbrasil.org.br/brasil-ocupa-o-4o-lugar-no-ranking-mundial-deconstrucoes-sustentaveis-certificadas-pela-ferramenta-internacional-leed>. Acesso em: 25 mai. 202I.

Seja nosso franqueado. Franchising book, 2020. Disponível em: < https://www.cacaushow.com.br/franquia.html>. Acesso em: I5 mai. 202I.

CAIXEIRO, Victor; RODRIGUES, Raphael. COMO FUNCIONA A FORMATAÇÃO DE FRANQUIAS: MARCA E ARQUITETURA. OMNIAC, 2020. Disponível em: < https://www.omniac.com.br/blog/como-funciona-a-formatacao-de-franquias-marca-earquitetura/\#: :text=Elabora\% $\mathrm{C}_{3} \% \mathrm{~A}_{7} \% \mathrm{C}_{3} \% \mathrm{~A}_{30} \% 20$ do\%2oprojeto\%20de\%20arquitetura\&t ext $=$ A\%20arquitetura\%20contribui\%2opara\%20que,de\%2oforma\%20coesa\%20e\%20s\% $\% 3 \%$ B 3 lida.\&text $=$ Por\%20isso\%2C\%20ao\%2oplanejar\%20uma,visual\%20e\%20valores\%20da\%20 marca.>. Acesso em: I6 mai. 2021.

COLOR in branding. Towergate Insurance, 2017. Disponível em: 〈https://www.towergateinsurance.co.uk/liability-insurance/professional-indemnityinsurance/colour-in-branding $>$. Acesso em: 15 mai. 2021.

COSTA, TAMARA; BEATI, André; MAGDALENA, RAFAEL. ESTRUTURAS PRÉMOLDADAS E OS IMPACTOS CAUSADOS NO SOLO. In: Encontro de Iniciação Cientifica, I2., 2016, São Paulo. Anais eletrônicos... São Paulo: USF, 2016. Disponível em: < https://www.usf.edu.br/ic_2or6/pdf/ic/meio-ambiente/ESTRUTURAS-PRE-

MOLDADAS-E-OS-IMPACTOS-CAUSADOS-NO-SOLO.pdf >. Acesso em: i mai. 2021.

Execução de projetos loja Provanza Center Shopping. Baruck Construtora, 2019. Disponível em: < https://www.baruckconstrutora.com/post/como-excluir-esse-post>. Acesso em: 27 mai. 2021.

FRANQUIAS: setor demonstra crescimento em meio à pandemia. Terra, 2021. Disponível em: <https://www.terra.com.br/noticias/dino/franquias-setor-demonstra-crescimentoem-meio-a-pandemia,I5f8a9ci28o9i4d49343rbaf73c8o654kzcj2wtu.html〉. Acesso em: 27 mai. 2021.

HARKLESS, Gresham. Psychology of Color Can Boost Your Marketing. Rescue, 2017. Disponível em: <https://rescue.ceoblognation.com/2017/12/o8/psychology-of-color-canboost-your-

marketing/\#: :text=Research\%20reveals\%2opeople\%20make\%20a,is\%20based\%200n\%20col or\%20alone>. Acesso em: 25 mai. 2021.

KOTLER, Philip. Atmospherics as a Marketing Tool. Journal of Retailing, Estados Unidos, v. 49 , n. 4, p.48-64, jan. 1974. 
LUCY, Marie. O Poder das Cores no Equilíbrio dos Ambientes. Rio de Janeiro: Pensamento, 1999.

Mariana Ulhôa Cintra. Cacau Show Café. Galeria da Arquitetura, 2013. Disponívem em: https://m.galeriadaarquitetura.com.br/slideshow/newslideshow. aspx?idproject $=2062 \&$ ind ex=I. Acesso em: o8 jun. 202I.

MORTON, Jill. Substantial research shows why color matters and how color plays a pivotal role in all our visual experiences. Colorcom, 2019. Disponível em: 〈https://www.colorcom.com/research/why-color-matters〉. Acesso em: 26 mai. 202I.

MOSER, Gabriel. Psicologia Ambiental. Estudos de Psicologia, Natal, v. 3, n. I, p. I21-130, 1998. Disponível em:

https://www.scielo.br/j/epsic/a/JJ6HsWrYfmYZy9XxZxtYVFr/?lang=pt\#>. Acesso em: 29 mar. 2021.

$\mathrm{Na}$ contramão da crise, Cacau Show planeja abrir mais 500 lojas em 2021. O São Gonçalo, 2021. Disponível em: < https://www.osaogoncalo.com.br/geral/ro2663/na-contramao-dacrise-cacau-show-planeja-abrir-mais-50o-lojas-em-202I>. Acesso em: I6 mai. 202I.

Nathalia Goulart. Os esmaltes da Provanza. Nathalia Gourlart, 2015. . Disponível em: < http://www.nathaliagoulart.com.br/2015/ro/os-esmaltes-da-provanza.html〉. Acesso em: I8 jun. 202I.

PLÁ, Daniel. Tudo Sobre Franchising. I. ed. Rio de Janeiro: Senac, 20or.

PROENCE, Juliana; FORASTIERI, Marcos; DOMINGUES, Carlos. DESIGN DOS FAST FOODS E A INFLUÊNCIA DAS CORES NOS AMBIENTES. Artigo (Graduação em Tecnólogo em Design de Interiores) - Faculdade do Norte novo de Apucarana, Paraná, 2019. Disponível em: <https://facnopar.com.br/conteudoarquivos/arquivo-2019-08-28-15670310663698.pdf >. Acesso em: I4 mai. 2021.

Quem somos. Provanza, 2021. Disponível em: < https://www.provanza.com.br/QuemSomos>. Acesso em: 27 mai. 2021.

RIBEIRO, Adir et al. Gestão Estratégica do Franchising: Como construir Redes de Franquia de Sucesso. 2. ed. São Paulo: DVS, 2013.

RISSATTO, Elaine. Identidade visual e expansão de franquias: entenda a relação. ER2 Arquitetura, 2020. Disponível em: 〈https://www.erzarquitetura.com.br/identidade-visuale-expansao-de-franquias-entenda-a-relacao>. Acesso em: I6 mai. 202I.

RISSATTO, Elaine. O que considerar para ter uma identidade arquitetônica única para a sua franquia?. ER2 Arquitetura, 2020. Disponível em: 
<https://www.erzarquitetura.com.br/o-que-considerar-para-ter-uma-identidadearquitetonica-unica-para-a-sua-franquia>. Acesso em: 16 mai. 202I.

SANTOS, Carlos. FATORES QUE INFLUENCIAM O CRESCIMENTO DO NÚMERO DE UNIDADES FRANQUEADAS NAS REDES BRASILEIRAS. Dissertação (Mestrado em Gestão de Negócios) - Fundação Instituto de Administração, São Paulo, 2017. Disponível em: <https://fia.com.br/wpcontent/uploads/2018/o7/Dissertacao-Carlos-Eduardo-Concli-dos-Santos.pdf〉. Acesso em: 20 mai. 2021. 